\title{
The effect of oceanic crust alteration on the global $\mathrm{W}$ budget
}

\section{RAMON REIFERÖTHER, CARSTEN MÜNKER AND FLORIAN KURZWEIL}

University of Cologne

Presenting Author: c.muenker@uni-koeln.de

Tungsten (W) behaves as a highly mobile element in the global geochemical cycle. Yet, its behaviour during hydrothermal alteration on the ocean floor has long remained unexplored. To assess the behaviour of $\mathrm{W}$ during oceanic crust alteration, we studied the behaviour of $\mathrm{W}$ and other highly incompatible elements such as $\mathrm{U}$, Th or $\mathrm{Ta}$ in samples from IODP drillholes covering representative sections of altered oceanic crust. Lavas and intrusives from upper basaltic oceanic crust exhibit W/Th as high as 1.4 , indicating an up to 10 fold enrichment of $\mathrm{W}$ relative to fresh MORB [1]. Tungsten enrichment is clearly linked to hydrothermal activity. In comparison to upper oceanic crust, rocks from the lower oceanic crust, i.e., abyssal peridotites and gabbros exhibit an even stronger $\mathrm{W}$ enrichment, with $\mathrm{W} / \mathrm{Th}$ as high as 200 , corresponding to a $\mathrm{W}$ enrichment factor of more than 100 . These observations indicate that altered oceanic crust is a major sink in the global geochemical cycle of $\mathrm{W}$ that also significantly contributes to the $\mathrm{W}$ enrichment observed in subduction zone lavas. To elucidate the origin of the excess $\mathrm{W}$ in altered oceanic crust, we performed stable $\mathrm{W}$ isotope measurements on selected samples. Samples from the upper oceanic crust exhibit $\delta^{186 / 184} \mathrm{~W}$ close to the modern mantle value of $+0.085 \pm 0.019 \%$ [2], whereas abyssal peridotites display larger alteration tending to lower $\delta^{186 / 184} \mathrm{~W}$ as low as -0.117 . The lighter $\mathrm{W}$ isotope composition can be attributed to distinct styles of alteration. We regard seawater as an unlikely source of the $\mathrm{W}$ enrichment, as seawater exhibits a distinct, high $\delta^{186 / 184} \mathrm{~W}$ of ca. $+0.55[3,4]$, which should have shifted the $\delta^{186 / 184} \mathrm{~W}$ W isotope composition of igneous rocks towards higher values during oceanic crust alteration. Hence, high-T hydrothermal redistribution of $\mathrm{W}$ and its enrichment near the seawater interface is the most likely process that can account for the observed, largely mantle-like $\mathrm{W}$ isotope patterns.

[1] König et al et al. (2011) GCA 75, 2119-2136. [2] Kurzweil et al. (2019) GCA 251, 176-191. [3] Fujiwara et al. (2020) Chem. Geol. 555, 119835. [4] Kurzweil et al. (2021), this meeting. 